\title{
Tradisi Wiwitan: Cara Penyebaran dan Proses Pembelajaran oleh Masyarakat (Studi Kasus: Dusun Kedon Desa Sumbermulyo, Kecamatan Bambanglipuro, Kabupaten Bantul)
}

\author{
The Wivitan Tradition: The Way to Disseminate of and The Learning Process by Community \\ (Case Study: Kedon Hamlet Sumbermulyo Village, Bambanglipuro Subdistrict, Bantul Regency)
}

Selamet Eko Edy Saputro, Dwiningtyas Padmaningrum, Arip Wijianto

Program Studi Penyuluhan dan Komunikasi Pertanian Fakultas Pertanian

Universitas Sebelas Maret

Jl. Ir. Sutami No.36 A Kentingan Surakarta 57126 Telp/Fax (0271) 637457

Email: ekoselamet21@yahoo.co.id

\begin{abstract}
The form of traditional knowledge that still persistence one is wiwitan tradition in Kedon Hamlet, Sumbermulyo Village, Bambanglipuro Subdistrict, Bantul Regency. The persistence of wiwitan tradition in Kedon Hamlet when the appreciation of cultural heritage generationsstarted to fade indicates that the presence of preservation efforts by the local community is still exist. Thisefforts can be done through learning and dissemination of wiwitan tradition by the local communities. Based on the idea this research aimed to; (1) determine how the communities of Kedon Hamlet, Sumbermulyo Village, Bambanglipuro Subdistrict Bantul Regency disseminate wiwitan tradition, (2) determine how the communities of Kedon Hamlet, Sumbermulyo Village, Bambanglipuro Subdistrict, Bantul Regencylearn wiwitan tradition. This research used a single case study method that examine the phenomenon of the persistence of wiwitan tradition. The data was collected by observation, documentation and indepth interview with informan. The determination informan conducted in purposive. Informan in the research are the head of Kedon Hamlet, chairman of the farmer groups, and the local communities. The data was analyzed using the model of interactive analysis Miles and Hubermen. This research showed that; (1) the communities of Kedon Hamlet disseminated wiwitan tradition in the form of cultural carnival, words of mouth and digital media, (2) the communities of Kedon Hamlet learned wiwitan tradition through social learning.
\end{abstract}

Keyword: Traditional Knowlegde; Wiwitan Tradition

\begin{abstract}
Abstrak: Bentuk pengetahuan tradisional yang hingga saat ini masih dapat bertahan salah satunya adalah tradisi wiwitan di Dusun Kedon, Desa Sumbermulyo, Kecamatan Bambanglipuro, Kabupaten Bantul. Tradisi wiwitan di Dusun Kedon masih bertahan disaat mulai lunturnya apresiasi terhadap budaya warisan generasi pendahulu. Hal ini menandakan adanya upaya pelestarian oleh masyarakat setempat. Upaya pelestarian tersebut dapat terwujud melalui pembelajaran dan penyebaran tradisi wiwitan oleh masyarakat setempat. Berdasarkan pemikiran tersebut maka penelitian ini bertujuan: (1) mengetahui cara penyebaran tradisi wiwitan oleh masyarakat Dusun Kedon, Desa Sumbermulyo, Kecamatan Bambanglipuro, Kabupaten Bantul, (2) mengetahui proses pembelajaran tradisi wiwitan oleh masyarakat Dusun Kedon, Desa Sumbermulyo, Kecamatan Bambanglipuro, Kabupaten Bantul. Penelitian ini menggunakan metode studi kasus tunggal yang mengkaji mengenai fenomena masih bertahannya tradisi wiwitan di Dusun Kedon, Kecamatan Bambanglipuro, Kabupaten Bantul. Pengumpulan data dilakukan melalui wawancara mendalam terhadap informan, observasi dan dokumentasi. Penentuan informan dilakukan secara sengaja. Informan dalam penelitian ini adalah Kepala Dusun Kedon, ketua kelompok tani dan masyarakat Dusun Kedon. Data dianalisis menggunakan model analisis interaktif oleh Miles dan Hubermen. Penelitian ini menunjukkan bahwa: (1) masyarakat Dusun Kedon menyebarkan tradisi wiwitan dalam bentuk kirab tradisi wiwitan, komunikasi getok tular dan melalui media digital (2) masyarakat Dusun Kedon mempelajari tradisi wiwitan melalui pembelajaran sosial.
\end{abstract}

Kata Kunci: Pengetahuan Tradisional; Tradisi Wiwitan 


\section{PENDAHULUAN}

Pengetahuan tradisional merujuk pada pengetahuan, inovasi dan praktik dari masyarakat asli atau lokal yang dikembangkan dari pengalaman dan di transmisikan secara lisan dari generasi ke generasi (Sucipto et al, 2016). Hal tersebut menandakan bahwa pengetahuan tradisional diperoleh melalui hasil belajar untuk kemudian disebarkan dalam suatu masyarakat.

Pengetahuan tradisional sebagai salah satu wujud budaya dapat disebarkan melalui proses difusi dan enkulturasi (Rachman, 2013). Difusi adalah proses penyebaran unsur kebudayaan dari satu individu ke individu lain atau dari satu masyarakat ke masyarakat lain. Enkulturasi adalah proses pembelajaran dan penyesuaian pikiran serta sikap seorang individu terhadapkebudayaannya.

Berkaitan dengan proses penyebaran dan pembelajaran kebudayaan Samovar et al (2010) mengemukakan bahwa kebudayaaan dapat disebarkan melalui berbagai bentuk (pepatah, cerita, karya seni) dan memiliki beragam agen penyebar (keluarga, teman, media, sekolah, gereja). Sebuah kebudayaan dapat dipelajari melalui pembelajaran formal (sekolah, gereja) dan melalui pembelajaran informal (interaksi, pengamatan, imitasi).

Pembelajaran informal dalam pembelajaran pengetahuan tradisional juga dapat berwujud pembelajaran social. Menurut Bandura dalam Ainiyah (2017), perilaku dan sikap seseorang tumbuh karena dorongan atau peneguhan dari orang-orang di sekitarnya. Tahapan-tahapan dalam pembelajaran sosial dimulai dari tahap perhatian, mengingat, reproduksi gerak dan motivasi.

Melalui proses pembelajaran dan penyebaran tersebut pengetahuan tradisional dapat terjaga kelestariannya. Hal tersebut dikarenakan dalam proses pembelajaran dan penyebaran pengetahuan tradisional dapat mentransmisikan nilai-nilai dalam pengetahuan tradisional yang membuat nilai-nilai tersebut tidak musnah. Menurut Samovar et al (2010), sebuah kebudayaan dapat dipertahankan apabila pesan dan elemen penting sebuah kebudayaan tidak hanya dibagikan melainkan diturunkan pada generasi selanjutnya.

\section{RUMUSAN MASALAH}

Salah satu bentuk pengetahuan tradisional yang hingga saat ini masih lestari adalah tradisi wiwitan di Dusun Kedon, Desa Sumbermulyo, Kecamatan Bambanglipuro, Kabupaten Bantul. Tradisi wiwitan di Dusun Kedon tersebut menandakan masih adanya upaya untuk mempelajari dan menyebarkan tradisi wiwitan oleh masyarakat setempat. Perumusan masalah dalam penelitian ini adalah cara masyarakat Dusun Kedon, Desa Sumbermulyo, Kecamatan Bambanglipuro, Kabupaten Bantul menyebarkan dan mempelajari tradisi wiwitan.

\section{METODE PENELITIAN}

Metode dasar yang digunakan dalam penelitian ini adalah studi kasus tunggal. Menurut Yin (2002), salah satu rasional untuk kasus tunggal adalah kasus tersebut menyajikan suatu kasus yang ekstrem atau unik. Pemilihan metode studi kasus tunggal dalam penelitian ini dilandasi pemikiran bahwa masih bertahannya tradisi wiwitan merupakan kasus yang unik.

Penentuan lokasi dilakukan secara purposive, yakni berdasarkan pertimbangan bahwa tradisi wiwitan di Dusun Kedon masih terjaga hingga saat ini dan tradisi wiwitan dikemas dalam bentuk kirab yang dapat disaksikan oleh khalayak luas.

Pemilihan informan dilakukan secara purposive. Informan yang dipilih adalah subjek yang bersedia untuk diwawancarai dan subjek tersebut mengetahui serta turut andil dalam pelaksanaan tradisi wiwitan di Dusun Kedon.

Pengumpulan data dilakukan dengan observasi, dokumentasi dan wawancara mendalam. Informan dalam penelitian ini adalah sesepuh Dusun Kedon dan petani di Dusun Kedon. Analisis data menggunakan model analisis interaktif oleh Miles dan Hubermen. 


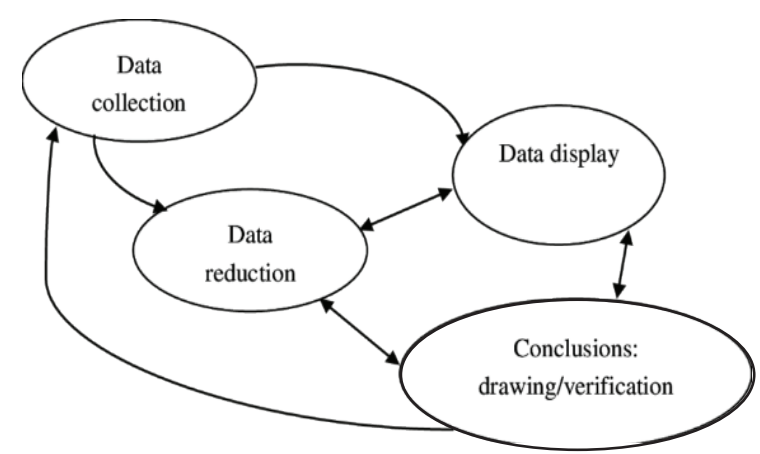

Gambar 2. Model Analisis Interaktif oleh Miles dan Hubermen dalam Sugiyono (2017)

\section{HASIL DAN PEMBAHASAN}

\section{Cara Masyarakat Dusun Kedon Menyebarkan Tradisi Wiwitan}

Sebuah tradisi dapat disebarkan dalam berbagai bentuk seperti cerita rakyat, syair, pertunjukan dan dongeng. Penyebaran tradisi tersebut dapat melalui berbagai agen penyebar seperti keluarga, media, teman, lingkungan tempat tinggal, sekolah dan sebagainya (Samovar et al, 2010).

Sebuah tradisi tidak hanya disebarkan kepada masyarakat dalam satu generasi, melainkan sebuah tradisi juga disebarkan kepada generasi selanjutnya atau diwariskan ke generasi selanjutnya. Pewarisan sebuah tradisi dari suatu generasi ke generasi selanjutnya menyebabkan sebuah tradisi dapat bertahan dari waktu ke waktu.

"Nggehmas, penyebaran nipun nggih diwujudke kaleh acara ting sabin niko mas. Supados sedoyo sami ngertos lan mirsani wiwitan niku punopo. Lan kagem regengipun ditambahi arakarakan gunungan hasil bumi paringipun sing kuwaos. Tiyang sepuh lan larelare sumerep lan nyekseni ontenipun acara wiwitan puniko. Sedoyo sami mangertos lan kasuwun lestareaken. Lan ugi sakniki kan acara wiwitan niko kalihan ngundang wartawan to mas, dadose nggih penyebaranipun saged lewat berita"

(S, 24 Mei 2018)
Masyarakat Dusun Kedon menyebarkan tradisi wiwitan dalam bentuk kirab, yakni perjalanan bersama-sama masyarakat dari dusun menuju areal persawahan. Sebelum kirab dimulai masyarakat Dusun Kedon berkumpul pada tempat yang telah ditentukan, kemudian masyarakat berdo'a agar tradisi wiwitan yang diselenggarakan dapat berjalan lancar. Selepas berdo'a, masyarakat memulai perjalanan dari Dusun menuju areal persawahan.

Perjalanan masyarakat dipimpin oleh punokawan (tokoh pewayangan Jawa), disusul oleh ubarampe (perlengkapan) dan beberapa gunungan seperti gunungan buah, gunungan sayur, dan gunungan padi juga turut dibawa dalam kirab tersebut. Gunungan-gunungan hasil bumi yang dibawa memiliki makna sebagai ungkapan rasa syukur petani terhadap sang pencipta. Gunungangunungan yang dibawa dalam kirab wiwitan Dusun Kedon dapat dilihat pada gambar 3.

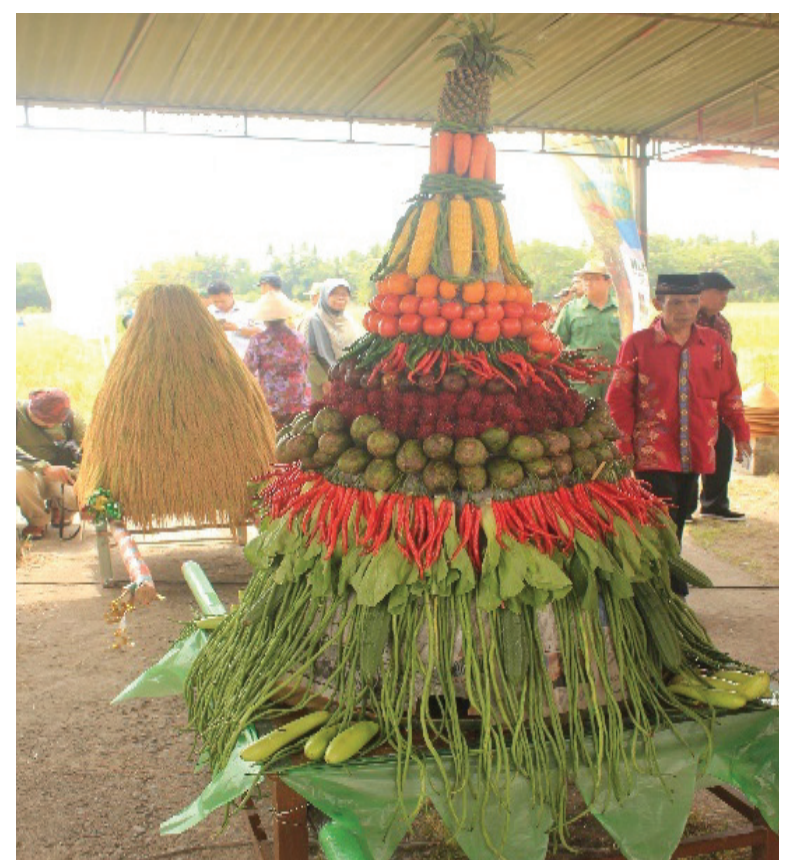

Gambar 3. Gunungan Buah, Sayur dan Padi pada Kirab Wiwitan

Bentuk kirab wiwitan tersebut pertama kali diusung sekitar 4 tahun yang lalu berdasarkan inisiatif masyarakat Kedon untuk menyajikan tradisi wiwitan dalam bentuk yang berbeda. Bentuk kirab tersebut sengaja dipertahankan oleh masyarakat Dusun Kedon karena bentuk kirab tersebut dapat menjadi salah satu sarana masyarakat di Dusun Kedon untuk bersilaturahmi. 
Kirab wiwitan dapat mengikat tali silaturahmi dan menarik perhatian khalayak luas sehingga tradisi wiwitan dapat tersebar secara lebih luas. Bentuk kirab dalam pelaksanaan tradisi wiwitan Dusun Kedon dapat dilihat pada gambar 4.

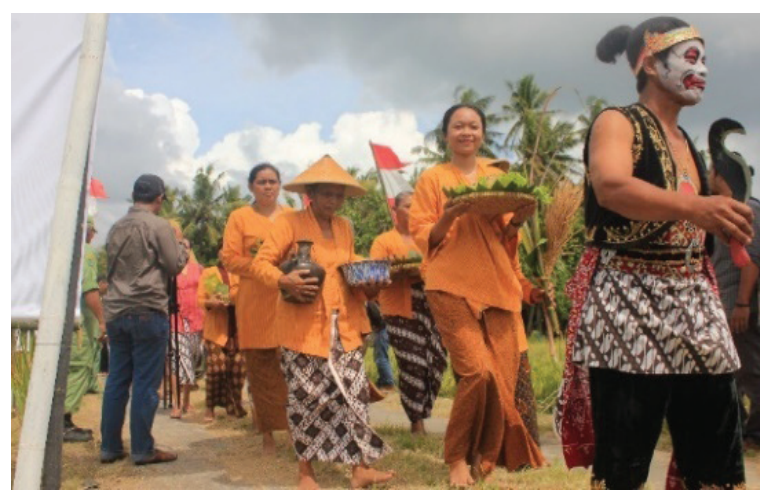

Gambar 4. Kirab Tradisi Wiwitan

Tradisi wiwitan dengan bentuk kirab ini selain menarik perhatian dari khalayak luas juga dijadikan strategi oleh masyarakat Dusun Kedon untuk menarik perhatian pemerintah setempat untuk mengikuti jalannya tradisi wiwitan. Beberapa wakil pemerintah yang datang dalam pelaksanaan tradisi wiwitan pada tanggal 11 Maret 2018 kemarin adalah perwakilan dari DPRD DIY, DPRD Kabupaten Bantul, Dinas Pertanian Pangan Kelautan dan Perikanan Kabupaten Bantul serta Musyawarah Pimpinan Kecamatan Bambanglipuro.

Wakil pemerintah yang hadir dalam pelaksanaan tradisi wiwitan Dusun Kedon menjadikan tradisi wiwitan tidak hanya sebagai sarana untuk mengucap syukur pada sang pencipta melainkan juga sebagai sarana diskusi petani dengan wakil pemerintah. Diskusi sektor pertanian dalam pelaksanaan tradisi wiwitan Dusun Kedon diharapkan dapat memajukan sektor pertanian Dusun Kedon. Beberapa wakil pemerintah yang datang dalam pelaksanaan tradisi wiwitan dapat dilihat di gambar 5 .

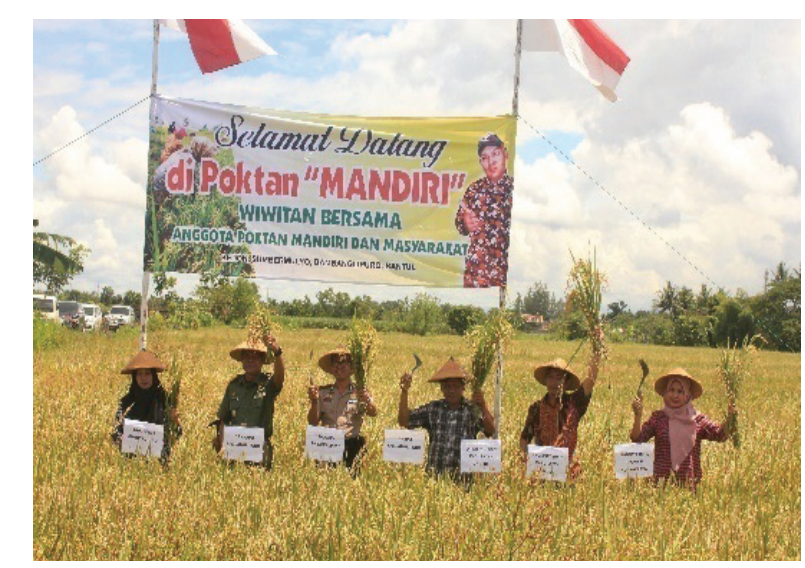

Gambar 5. Wakil Pemerintah yang Hadir dalam Tradisi Wiwitan

Penyebaran selanjutnya adalah melalui komunikasi getok tular dan melalui media digital. Komunikasi getok tular dalam penyebaran tradisi wiwitan Dusun Kedon tersebut bermula dari pertemuan kelompok Tani Mandiri di Dusun Kedon yang merencanakan untuk menggelar tradisi wiwitan. Petani yang hadir dalam pertemuan tersebut membawa informasi mengenai segera dilaksanakannya tradisi wiwitan dan disampaikan kepada keluarga di rumah. Informasi mengenai pelaksanaan tradisi wiwitan tersebut kemudian menyebar di Dusun Kedon yang membuat masyarakat Dusun Kedon secara keseluruhan mengetahui informasi adanya gelar tradisi wiwitan. Sistem sosial masyarakat Dusun Kedon yang bersifat kolektif mendukung penyebaran melalui komunikasi getok tular.

Penyebaran tradisi wiwitan selanjutnya adalah melalui media digital. Menurut Meilani (2014), media digital merupakan bentuk media elektronik yang tidak menyimpan data dalam bentuk analog. Media digital yang digunakan masyarakat dalam menyebarkan tradisi wiwitan adalah internet dan jejaring sosial. Penggunaan media digital dalam penyebaran tradisi wiwitan Dusun Kedon tersebut mengakibatkan semakin luasnya penyebaran tradisi wiwitan. Semakin luasnya penyebaran tradisi wiwitan Dusun Kedon mengakibatkan semakin banyak pula orang yang mengetahui adanya tradisi wiwitan Dusun Kedon sehingga dapat meminimalisir pengklaiman tradisi wiwitan oleh bangsa asing.

Tidak hanya disebarkan dalam masyarakat pada satu generasi tradisi wiwitan juga diwariskan kepada generasi selanjutnya maupun masyarakat luas di luar masyarakat 
Dusun Kedon. Pewarisan tersebut tercermin dari pemilihan hari libur sekolah dalam pelaksaaan wiwitan yang dapat menarik minat anak-anak yang masih bersekolah untuk mengikuti jalannya tradisi wiwitan. Antuasiasme anak-anak dalam mengikuti jalannya tradisi wiwitan dapat dilihat pada gambar 6 .

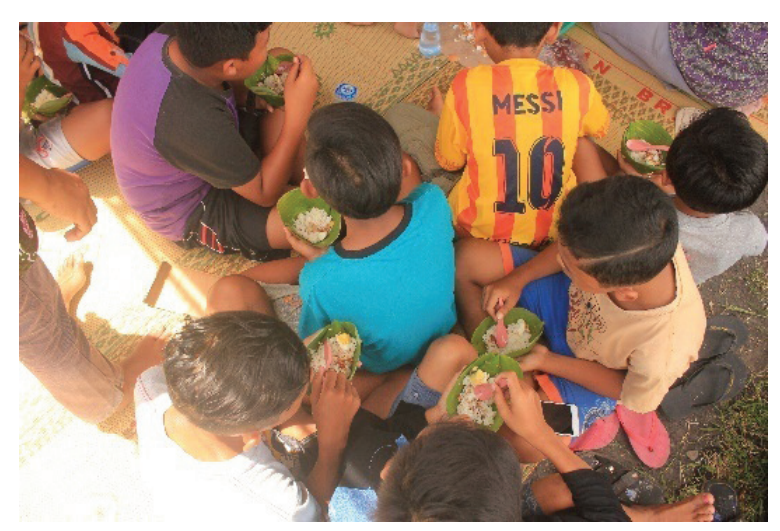

Gambar 6. Antusiasme Anak dalam Tradisi wiwitan

\section{Proses Pembelajaran Tradisi Wiwitan oleh Masyarakat Dusun Kedon}

Tradisi dapat dipelajari melalui berbagai macam proses belajar. Samovar et al (2010) mengemukakan bahwa pembelajaran kebudayaan dapat ditempuh melalui pembelajaran formal maupun pembelajaran informal. Pembelajaran formal adalah pembelajaran yang lebih terstruktur, misalnya pembelajaran budaya di sekolah atau di gereja. Pembelajaran informal merupakan pembelajaran yang tidak terstruktur yang sulit untuk dikenali, pembelajaran tersebut dapat terjadi setiap saat seperti saat menonton tv, mendengarkan musik dan lain sebagainya.

Salah satu bentuk pembelajaran informal adalah pembelajaran sosial (social learning). Bandura dalam Ainiyah (2017) mengemukakan bahwa perilaku dan sikap seseorang tumbuh karena dorongan atau peneguhan dari orangorang di sekitarnya. Proses pembelajaran sosial tersebut memiliki 4 tahapan yaitu tahap perhatian, mengingat, reproduksi gerak dan motivasi.

Tahap perhatian adalah individu cenderung memerhatikan tingkah laku model untuk dapat mempelajarinya. Tahap mengingat adalah individu yang sedang belajar harus merekam peristiwa yang ingin ditiru dalam sistem ingatannya. Tahap reproduksi gerak adalah tahapan setelah mengetahui atau mempelajari suatu tingkah laku, individu juga cenderung menunjukkan kemampuannya atau menghasilkan kembali apa yang diingat dalam bentuk tingkah laku. Tahap motivasi adalah penggerak individu untuk terus melakukan sesuatu.

\begin{abstract}
"Ya, dari orang-orang tua dulu mas. Jadi orang tua-orang tua dulu kan sebelum panen padi melakukan tradisi wiwitan mas. Nah kita sebagai anak ya mesti meniru orang tua dulu to mas. Apalagi tradisi wiwitan itu kan mengajarkan kebaikan, rasa syukur kita kepada Allah SWT, terus mengajarkan keguyub-rukun dan itujuga kan sebagai simbol bahwa ini lho wong deso, wong sing guyub rukun adem ayem tentrem"
\end{abstract}

(O, 11 Maret 2018)

Masyarakat Dusun Kedon mempelajari tradisi wiwitan melalui pembelajaran sosial (social learning). Menurut Bandura dalam Ainiyah (2017), pembelajaran sosial memiliki empat tahapan dalam proses pembelajaran yaitu tahap perhatian, mengingat, reproduksi gerak dan motivasi.

Tahap perhatian dalam proses pembelajaran tradisi wiwitan terjadi ketika masyarakat Dusun Kedon mengamati jalannya tradisi wiwitan yang diselenggarakan oleh generasi pendahulunya. Pengamatan tersebut terjadi ketika masyarakat Dusun Kedon mengikuti jalannya tradisi wiwitan yang diselenggarakan oleh orang tuanya. Pengamatan dilaksanakan selama bertahun-tahun karena tradisi wiwitan dilaksanakan oleh petani setiap hendak memanen hasil sawahnya.

Tahapan selanjutnya adalah mengingat, tahapan ini terjadi ketika masyarakat mengingat prosesi wiwitan yang dilaksanakan oleh generasi pendahulunya. Ingatan tersebut semakin kuat dikarenakan tradisi wiwitan dilaksanakan setiap petani hendak memanen padi. Tahap perhatian dalam pembelajaran tradisi wiwitan dapat dilihat pada gambar 7 . 


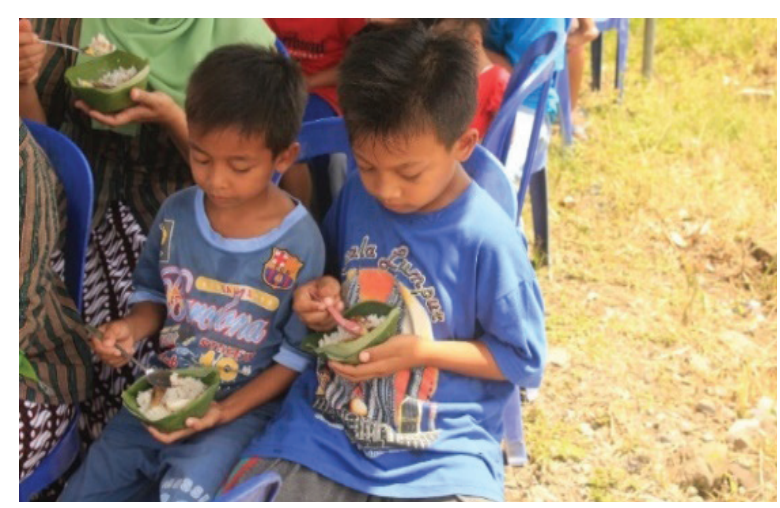

Gambar 7. Anak-anak yang Berparisipasi pada Tradisi Wiwitan

Tahapan reproduksi gerak adalah tahapan meniru. Tahapan ini terjadi ketika masyarakat Dusun Kedon meniru pelaksanaan tradisi wiwitan yang dilakukan oleh generasi pendahulunya. Masyarakat Dusun Kedon mampu meniru penyelenggaraan tradisi wiwitan melalui proses pengamatan dan proses mengingat yang telah lebih dulu dilaksanakan. Motivasi masyarakat dalam mempelajari tradisi wiwitan adalah persepsi atau pandangan bahwa tradisi wiwitan itu mengajarkan kebaikan.

Pembelajaran sosial dalam tradisi wiwitan memerlukan dukungan semua pihak. Generasi saat ini harus senantiasa melestarikan tradisi wiwitan agar generasi selanjutnya mengetahui ide dan nilai-nilai dalam tradisi wiwitan. Dukungan dan apresiasi dari pemerintah dapat menjadikan tradisi wiwitan tersebut lestari hingga di masa yang akan datang.

Masyarakat Dusun Kedon mempelajari tradisi wiwitan dari generasi pendahulunya untuk kemudian diterapkan pada zaman sekarang, membuat tradisi wiwitan mengalami dinamika atau perubahan. Dinamika dalam pelaksanaan tradisi wiwitan dapat tercermin dari tujuan awal digelarnya tradisi wiwitan, waktu dan tempat yang digunakan serta pelaku pelaksanaan dalam tradisi wiwitan.

Tujuan awal tradisi wiwitan adalah sebagai wujud syukur petani terhadap Dewi Sri. Tujuan tersebut kini berubah menjadi wujud syukur petani kepada Allah SWT dan sebagai sarana diskusi petani dengan wakil dari pemerintah. Bentuk wiwitan zaman sekarang adalah kirab. Pelaku tradisi wiwitan adalah masyarakat Dusun Kedon secara keseluruhan. Berbeda dengan pelaksaan tradisi wiwitan zaman dahulu dimana pelaku tradisi wiwitan hanyalah petani beserta dengan keluarganya.

Wiwitan dikemas dalam bentuk kirab yang dilaksanakan oleh masyarakat Dusun Kedon secara keseluruhan, sehingga tempat dan waktu dipilih berdasarkan kesepakatan bersama dari masyarakat Dusun Kedon. Tempat pelaksanaan tradisi wiwitan dipilih berdasarkan letak yang strategis sehingga mudah dijangkau oleh masyarakat, kemudian pemilihan hari atau waktu dalam pelaksanaan tradisi wiwitan adalah hari Minggu dengan alasan agar anak-anak dari masyarakat yang masih mengeyam pendidikan dapat meingikuti pelaksanaan tradisi wiwitan.

\section{KESIMPULAN DAN SARAN}

\section{Kesimpulan}

Penelitian menunjukkan bahwa masyarakat Dusun Kedon, Desa Sumbermulyo, Kecamatan Bambanglipuro, Kabupaten Bantul menyebarkan tradisi wiwitan dalam bentuk kirab wiwitan yaitu perjalanan bersama-sama masyarakat Dusun Kedon dari areal Dusun menuju areal persawahan, komunikasi getok tular yaitu komunikasi yang beredar dari mulut ke mulut dan melalui media digital yaitu internet dan jejaring sosial. Penyebaran menggunakan internet dapat memperluas jangkauan penyebaran tradisi sehingga dapat meminimalisir pengklaiman tradisi wiwitan oleh bangsa asing.

Proses pembelajaran wiwitan oleh masyarakat Dusun Kedon adalah melalui pembelajaran sosial (social learning). Pembelajaran sosial memiliki beberapa tahapan yaitu perhatian, mengingat, reproduksi gerak dan motivasi. Tahap perhatian terjadi pada saat masyarakat Dusun Kedon mengikuti jalannya tradisi wiwitan oleh generasi pendahulunya. Tahap mengingat terjadi setelah masyarakat Dusun Kedon melihat jalannya tradisi wiwitan. Tahap reproduksi gerak terjadi ketika masyarakat Dusun Kedon meniru penyelenggaraan tradisi wiwitan oleh generasi pendahulunya. Tahap motivasi bersumber pada pandangan bahwa wiwitan merupakan hal yang baik untuk dilakukan. 


\section{Saran}

Berdasarkan hasil penelitian di atas maka masyarakat Dusun Kedon, Desa Sumbermulyo, Kecamatan Bambanglipuro, Kabupaten Bantul perlu untuk meningkatkan penggunaan media digital dalam menyebarkan tradisi wiwitan. Peningkatan tersebut perlu dilakukan mengingat media digital dapat menjangkau khalayak lebih luas. Peningkatan penggunaan media digital dapat diwujudkan dengan membuat fanspage di beberapa jejaring sosial seperti Instagram, facebook, dan lain sebagainya agar masyarakat di daerah lain dapat terinspirasi untuk senantiasa melestarikan budaya atau tradisi warisan generasi pendahulunya. Publikasi tradisi melalui jejaring sosial oleh masyarakat dapat meminimalisir tindakan pencurian warisan kebudayaan oleh bangsa asing.

\section{DAFTAR PUSTAKA}

Ainiyah, Qurotul. 2017. Social Learning Theory dan Perilaku Agresif Anak dalam Keluarga. Jurnal Ilmu Syariah dan Hukum Volume 2 N0 1.

Meilani. 2014. Berbudaya Melalui Media Digital. Humaniora Volume 5 N0 2.

Samovar et al. Komunikasi Lintas Budaya Edisi 7. Salemba Humanika. Jakarta.

Yin, Robert K. 2002. Studi Kasus (Desain \& Metode). Raja Grafindo Persada. Jakarta.

Suradi. 2016. Bentuk Komunikasi dalam Menjalankan Proses Enkulturasi Budaya (Studi Pada Masyarakat Suku Dayak Kenyah di Desa Pampang, Kecamatan Samarinda Utara). eJournal Ilmu Komunikasi Volume 4 No 1.

Rachman, Maman. 2013. Pengembangan Pendidikan Karakter Berwawasan Konservasi Nilai-nilai Sosial. Forum Ilmu Sosial Volume 40 No 1.

Harjanto dan Mulyana. 2008. Komunikasi Getok Tular Pengantar Popularitas Merk. Mediator Volume 9 No 2.
Indriyawati, Emmy. 2009. Antropologi Jilid 1. Penerbit Pusat Perbukuan. Depdiknas. Jakarta.

Sucipto et al. 2016. Analisis Konteks Pengetahuan dan Ekspresi Budaya Tradisional BerbasisMuatan Lokal Provinsi Jawa Barat. Kementerian Pendidian dan Kebudayaan. Bandung.

Sugiyono. 2017. Metode Penelitian Kuantitatif, Kualitatif dan $R \& D$. Alfabeta. Bandung. 